\title{
CORRESPONDENCE
}

\section{Air travel and hypoxaemia in real life}

\section{To the Editors:}

We read with great interest the paper by COKER et al. [1] in an issue of the European Respiratory Journal.

The authors conducted the largest prospective study into the outcomes of flights in patients with various respiratory diseases, showing that $18 \%$ suffered respiratory symptoms. They concluded that, although air travel seems generally safe in this population of patients under specialist respiratory care, more detailed studies with oximetry monitoring during flight should be performed to determine which patients are most at risk.

The evaluation of the risk of in-flight hypoxaemia has been determined by studies performed in altitude chambers or by hypoxic gas mixture challenge [2]. However, extrapolating the findings to real flights may be misleading, due to the higher altitudes attained by newer aircraft, longer duration of altitude exposure and passengers' activity inside the aircraft [3].

We have evaluated transcutaneous arterial oxygen saturation $\left(\mathrm{Sa}, \mathrm{O}_{2}\right)$ using Pulsox 3iA (Minolta, Tokyo, Japan), a finger pulse oximeter with a 24-h internal memory and dedicated software (Pulsox DS-3; Minolta) for viewing and analysis of the recordings. Data was acquired from 10 healthy adults (medical staff from the Dept of Pulmonology, Faculty of Medicine, University of Porto, Hospital de São João, Porto, Portugal) with a mean \pm SD age of $38.9 \pm 13.1$ yrs, of whom four were female and six were male. Measurements were started just before take-off and ended after landing, for 20 commercial longdistance flights (LFs; $\geqslant 2 \mathrm{~h}$ ) and 18 short-distance flights (SFs; $<2 \mathrm{~h}$ ). Each subject wore the oximeter in a wristband and was able to mark an event by pressing a small button on it each time they were involved in an activity, such as eating, walking and going to the lavatories. After the return flight, all stored data were downloaded on to a computer, producing a cumulative distribution graph $\left(\mathrm{Sa}_{2} \mathrm{O}_{2}\right.$ and pulse rate, with events marked) and saturation parameters analysis (mean, minimum, $\mathrm{Sa}_{\mathrm{a}} \mathrm{O}_{2}$ dips, time spent with $\mathrm{Sa}_{\mathrm{O}_{2}}<90 \%$ ).

The investigation was carried out in different aircraft models of European and American airline companies in round-trip flights: 10 flights in Airbus A320; nine flights in Airbus A310; one flight in Airbus A319; eight flights in Fokker 100; three flights in Boeing 737; two flights in Boeing 757; one flight in Boeing 777; two flights in McDonnell Douglas; and two flights in BA200. Examples of LFs were Lisbon-New York, Los Angeles-Paris, New York-San Francisco and Porto-Berlin; SFs were LisbonRome, Porto-Paris, Porto-Lisbon and New York-Toronto.

The mean \pm SD (range) monitoring duration for LFs was $5.1 \pm 2.2$ (2.2-9.2) $\mathrm{h}$ and for SFs was $1.0 \pm 0.6(0.5-2.0) \mathrm{h}$. On average, the maximal desaturation (difference between baseline and minimum $\mathrm{Sa}_{2} \mathrm{O}_{2}$ ) achieved was $12.8 \pm 6.3 \%$ for $\mathrm{LFs}$ and $4.2 \pm 2.6 \%$ for $\mathrm{SFs}(\mathrm{p}=0.001)$. While in all LFs, subjects reached a minimum $\mathrm{Sa}_{2} \mathrm{O}_{2}$ $\leqslant 90 \%$ (mean \pm SD $85.5 \pm 5.3 \%$ ), in only four $(22.2 \%)$ SFs did the subjects develop a minimum $\mathrm{Sa}_{\mathrm{O}_{2}}<90 \%$ (mean $\pm \mathrm{SD} 93.0 \pm 2.7 \%$ ). Although the proportion of time spent with $\mathrm{Sa}_{\mathrm{a}_{2} \mathrm{O}_{2}}<90 \%$ was small $(0.7 \pm 0.9 \%$ in LFs), in some flights (two trans-Atlantic and one Porto-Berlin) this level was attained for $>5 \mathrm{~min}$. In some cases, we also found repetitive oscillations in $\mathrm{Sa}_{1} \mathrm{O}_{2}$ signal (fig. 1); in fact, considering $4 \%$ dips, LFs had significantly more dips per hour than SFs $(3.1 \pm 3.0$ versus $0.4 \pm 0.8 ; \mathrm{p}<0.001)$. On three occasions (on a New York-Lisbon flight and in two subjects on a Porto-Berlin flight) it reached $>5 \mathrm{dips} \cdot \mathrm{h}^{-1}$. By visual inspection of the $\mathrm{Sa}, \mathrm{O}_{2}$ trends during LFs, we could not see a stabilisation of $\mathrm{Sa}_{1} \mathrm{O}_{2}$ at maximum altitude in all cases: in four cases, $\mathrm{Sa}_{2} \mathrm{O}_{2}$ progressively declined until the flight descent began.

We also observed that $\mathrm{Sa}_{2} \mathrm{O}_{2}$ dropped during meals, walking along the aisle and especially in the lavatories (fig. 1). In fact, in seven LFs it was possible to mark an event while the subject was in the lavatories, and $\mathrm{Sa}_{1} \mathrm{O}_{2}$ on that occasion was always close to the minimum (range 83.3-92.8\%).

Oxygen desaturation values observed in our study seem variable between subjects, flights and planes. The greater desaturation during LFs in healthy subjects is consistent with the data of COKER et al. [1], who reported worsening symptoms mainly in patients in whom average flight duration was $7.6 \mathrm{~h}$. As intermittent hypoxia is an effective stimulus for evoking cardiorespiratory responses, repetitive $4 \%$ desaturations (an

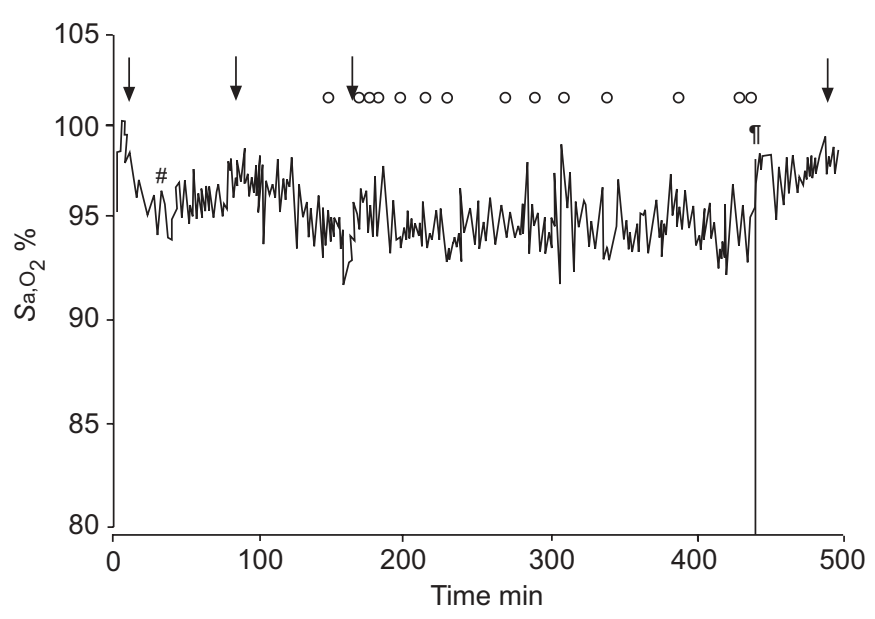

FIGURE 1. Changes in transcutaneous arterial oxygen saturation $\left(\mathrm{Sa}, \mathrm{O}_{2}\right)$ of one subject during a flight from Lisbon to New York. Arrows indicate events as follows: take-off, lunch, lavatory visit and landing. The baseline $\mathrm{Sa}, \mathrm{O}_{2}$ was $98 \%$; after take-off it dropped to $95 \%\left({ }^{\#}\right)$. In the lavatories there was an intense desaturation to $91 \%$. When descent began, $\mathrm{Sa}_{2} \mathrm{O}_{2}$ increased, attaining $98 \%$ at landing. Apart from progressive decline of $\mathrm{Sa}, \mathrm{O}_{2}$, repetitive $4 \%$ dips were also seen $\left(1.5 \mathrm{dips} \cdot \mathrm{h}^{-1}\right) . \mathrm{O}$ : movement artefacts. ${ }^{\bullet}$ : the last movement artefact coincided with an abrupt fall in $\mathrm{Sa}, \mathrm{O}_{2}$. Measurement started at 14:00 h 
original finding) may also contribute to the detrimental effects of air travel [4].

In conclusion, we believe that oxygen saturation levels obtained in real life may be very useful for monitoring the health impact of flying and an important measurement to better determine patients at risk.

\section{J.C. Winck, M. Drummond, J. Almeida and J.A. Marques} Dept of Pulmonology, Faculty of Medicine, University of Porto, Hospital de São João, Porto, Portugal.

\section{STATEMENT OF INTEREST}

None declared.

\section{Diffuse panbronchiolitis}

\section{To the Editors:}

MCGRATH et al. [1] recently reported the case of a middle-aged Caucasian female with a diagnosis of diffuse panbronchiolitis (DPB) and highlighted the difficulties of securing such a diagnosis in populations in which it is rarely described, i.e. those of Western/non-Asian origin. This was in response to a narrative review by POLETTI et al. [2] describing current diagnostic criteria and demographic features. We would like to emphasise this point in describing the case of a 45-yr-old English-born Caucasian male who was recently assessed and

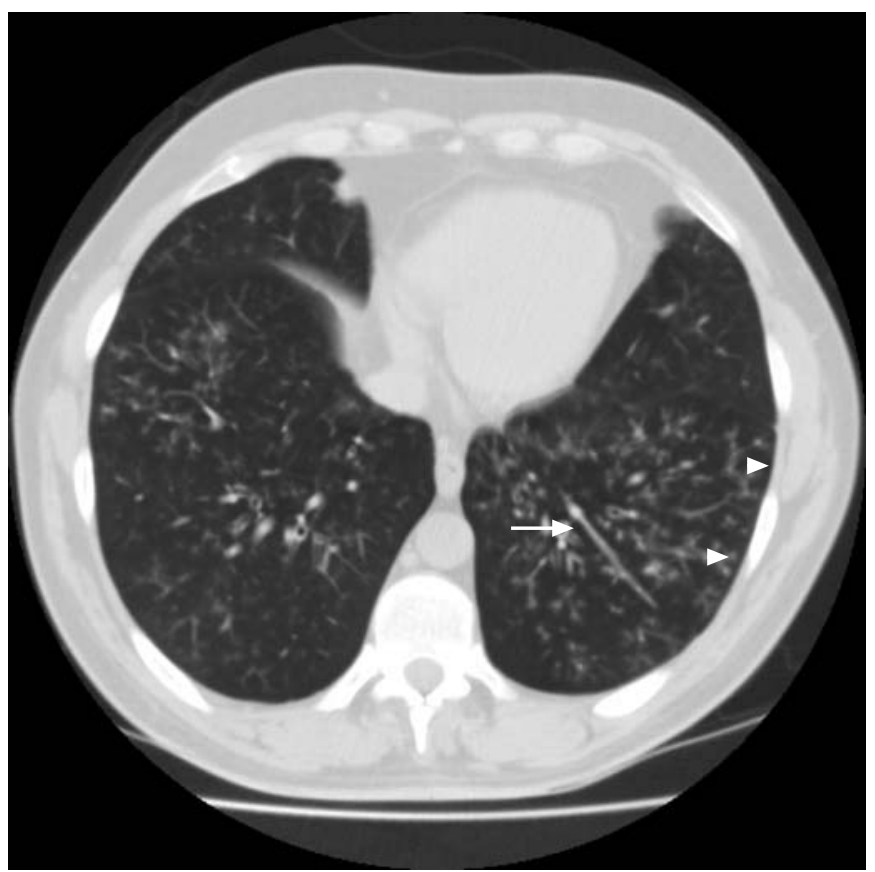

FIGURE 1. High resolution computed tomography image showing extensive small airway plugging with a "tree-in-bud" pattern (white arrowheads) associated with early lower lobe bronchiectasis (white arrow)

\section{REFERENCES}

1 Coker RK, Shiner RJ, Partridge MR. Is air travel safe for those with lung disease? Eur Respir J 2007; 30: 1057-1063.

2 Dillard TA, Moores LK, Bilello KL, Phillips YY. The preflight evaluation. A comparison of the hypoxia inhalation test with hypobaric exposure. Chest 1995; 107: 352-357.

3 Cottrell JJ. Altitude exposures during aircraft flight. Flying higher. Chest 1988; 93: 81-84.

4 Neubauer JA. Invited review: Physiological and pathophysiological responses to intermittent hypoxia. J Appl Physiol 2001; 90: 1593-1599.

DOI: $10.1183 / 09031936.00001708$

treated at our centre. The patient was a lifelong nonsmoker with no Asian ancestry and had never travelled outside Europe. He had been referred to the respiratory clinic by his primary care physician on account of a 3-yr history of worsening exertional breathlessness and chronic productive cough associated with persistent, purulent rhinorrhoea. His symptoms had persisted and indeed worsened in the face of treatment with a high dose inhaled corticosteroid (ICS) used in conjunction with a long-acting $\beta_{2}$-agonist (LABA) with repeated courses of oral corticosteroids. At first assessment, bibasal crackles and wheeze were present on examination of the chest. Spirometry revealed a moderately severe obstructive pattern with a forced expiratory volume in one second (FEV1) of $1.7 \mathrm{~L}$ (55\% pred), a forced vital capacity (FVC) of $3.1 \mathrm{~L}(78 \%$ pred). Plain chest radiograph revealed bibasal nodular infiltrates and Haemophilus influenzae was isolated on culture of sputum and bronchoalveolar lavage fluid. High-resolution

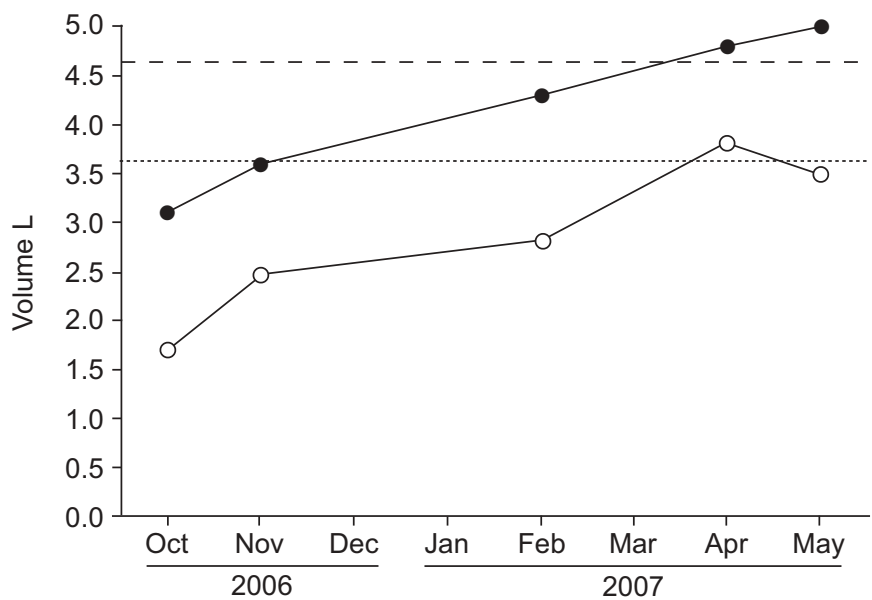

FIGURE 2. Forced expiratory volume in one second $\left(\mathrm{FEV}_{1} ; \bigcirc\right)$ and forced vital capacity (FVC; -) from October 2006 to May 2007 of a 45-yr-old English-born Caucasian male. …: predicted $\mathrm{FEV}_{1} ;$. . . . - : predicted FVC. 